\title{
Simulation and optimization of airlift external circulation membrane bioreactor using computational fluid dynamics
}

\author{
Zhang Qing, Xu Rongle, Zheng Xiang and Fan Yaobo
}

\begin{abstract}
The airlift external circulation membrane bioreactor (AEC-MBR) is a new MBR consisting of a separated aeration tank and membrane tank with circulating pipes fixed between the two tanks. The circulating pipe is called a $\mathrm{H}$ circulating pipe (HCP) because of its shape. With the complex configuration, it was difficult but necessary to master the AEC-MBR's hydraulic characteristics. In this paper, simulation and optimization of the AEC-MBR was performed using computational fluid dynamics. The distance from diffusers to membrane modules, i.e. the height of gas-liquid mixing zone $\left(h_{m}\right)$, and its effect on velocity distribution at membrane surfaces were studied. Additionally, the role of HCP and the effect of HCP's diameter on circulation were simulated and analyzed. The results showed that non-uniformity of cross-flow velocity existed in the flat-plate membrane modules, and the problem could be alleviated by increasing $h_{m}$ to an optimum range $\left(h_{m} / B \geq 0.55 ; B\right.$ is total static depth). Also, the low velocity in the boundary layer on the membrane surface was another reason for membrane fouling. The results also suggested that HCP was necessary and it had an optimum diameter to make circulation effective in the AEC-MBR.

Key words | airlift external circulation membrane bioreactor, computational fluid dynamics, height of gas-liquid mixing zone, $\mathrm{H}$ circulating pipe
\end{abstract}

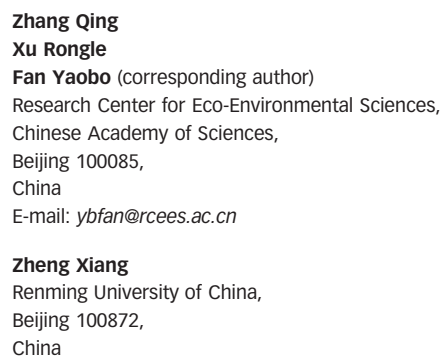

\section{INTRODUCTION}

The current membrane bioreactors (MBRs) are classified into two major groups according to their configuration: the external MBRs with convenient membrane cleaning or maintenance, and the submerged MBRs with low operation cost (Judd \& Judd 20II). For studying the MBR with combined properties and the advantages of both the conventional external and submerged MBRs, a new type of MBR named airlift external circulation membrane bioreactor (AEC-MBR) was developed, which had an aeration tank and a membrane tank separated by a baffle, and $\mathrm{H}$ circulation pipes (HCPs) were installed between the tanks. Generally, two or more HCPs are adopted in one AECMBR system. The HCP is so named because it has two legs with a horizontal connecting pipe and its shape looks like the letter 'H' (Figure 1(a)) (Fan et al. 2006). Under the drive of aeration intensity difference between the aeration tank and the membrane tank, the mixture in AEC-MBR flowed from the bottom of the aeration tank to that of the membrane tank through the HCPs, then rose up and passed through the membrane modules, finally running back to the aeration tank over the top of the baffle. The aeration in the membrane tank had three functions: maintaining dissolved oxygen (DO) concentration for activities of activated sludge, scouring membrane surface and promoting circulation in AEC-MBR. Without a recycling pump, the energy consumption of AEC-MBR was much lower than that of a conventional external MBR. Moreover, the membrane cleaning/maintenance could be easily performed online without stopping the running of the aeration tank. When the membrane needed chemical cleaning, the membrane tank could be separated from the aeration tank simply by lowering the water level. Since 2003, AEC-MBR has been applied in more than 40 plants for treatment and reuse of wastewater from wash rooms, hospitals, pharmaceutical factories and residential buildings in China.

However, the current design of AEC-MBR was largely based on assumptions for a desired flow regime (e.g. complete mixing) and empirical techniques (e.g. specific mixing energy). For example, the lack of information on the design of the aerators in a membrane tank stood out 
(a)

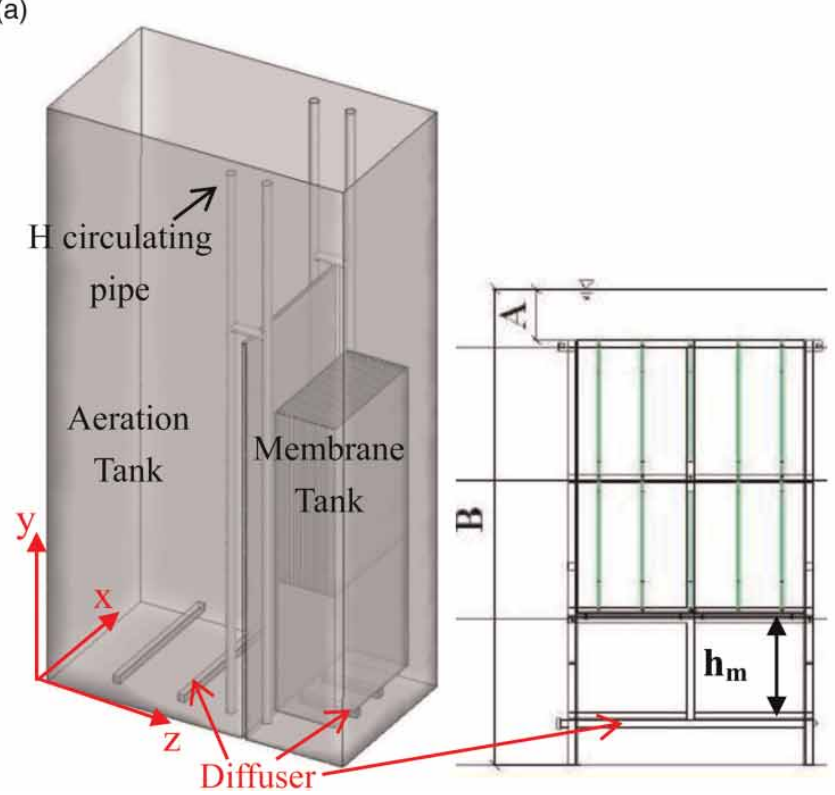

(b)

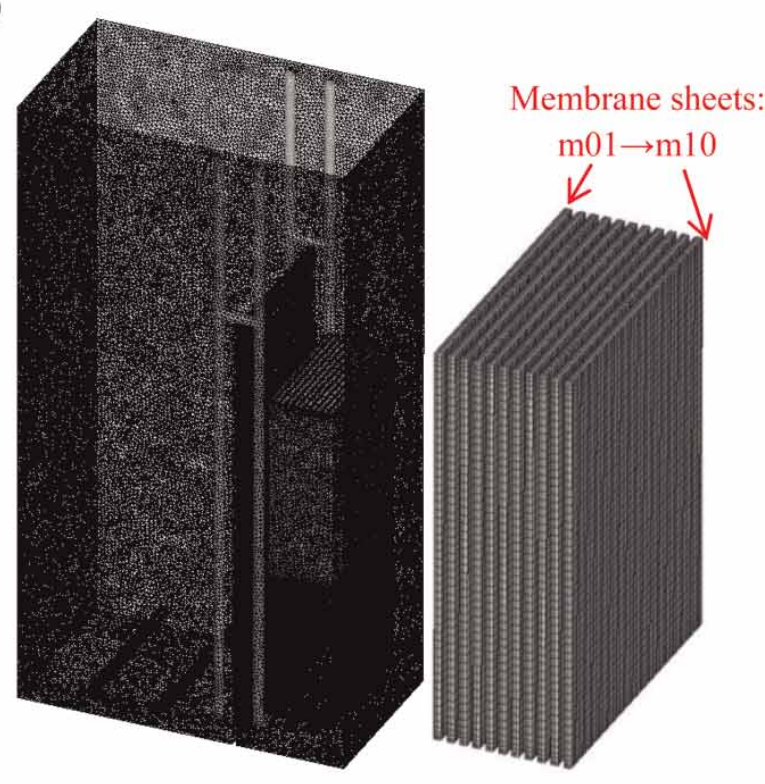

Figure 1 | (a) Geometrical configuration of AEC-MBR. A - distance from free surface to top membrane, B - total static depth, $\mathrm{h}_{\mathrm{m}}$ - height of gas-liquid mixing. (b) Global mesh of MBR and local mesh of membrane module.

most prominently. The aerators were always installed under the membrane modules while the distance to the membrane modules was often set empirically, due to the hydrodynamics in AEC-MBR being poorly understood, such as on the distribution of mixture velocity, cross-flow velocity $(\mathrm{CFV})$ and shear stress at the membrane surface, even though they were of critical importance to performance. To address the hydrodynamic problems, computational fluid dynamics (CFD) is a powerful tool helpful for understanding the flow field in MBRs. CFD can overcome some difficulties consisting of theory and experiment, such as analyzing the $\mathrm{CFV}$ at the membrane surface, and studying the effect of geometry/configuration on bioreactor hydrodynamics efficiently and economically (Khalili-Garakani et al. 20II). Recently, a vast amount of research on CFD modeling of MBRs has been published (Ndinisa et al. 2006; Nguyen Cong Duc 2007; Nguyen Cong Duc et al. 2008; Kang et al. 2008; Prieske et al. 2008; Saalbach \& Hunze 2008; Brannock et al. 2009, 2010a, 2010b; Khalili-Garakani et al. 20II), which provides good reference for the application and development of the technology.

The objective of this paper was to reveal some key hydrodynamic reasons leading to serious membrane fouling by studying the effect of the aeration system on the velocity distribution at the membrane surface, and to optimize the key structure of AEC-MBR. Five cases with different diffuser configurations in the membrane tank were simulated, and the impact on membrane fouling control was analyzed.
Meanwhile, the role of HCP and the effect of different HCP diameters on circulation between the membrane tank and the aeration tank were modeled and are discussed.

\section{METHODS}

\section{Experimental set-up}

CFD simulations were carried out on a modeled AEC-MBR (Figure 1); the specifications of the AEC-MBR are shown in Table 1.

Table 1 | Configuration of AEC-MBR for CFD simulation

\begin{tabular}{ll} 
Items & Parameters \\
\hline Scale & $1 \mathrm{t} / \mathrm{d}$ \\
Width $\times$ length $\times$ height & $0.450 \mathrm{~m} \times 0.820 \mathrm{~m} \times 1.700 \mathrm{~m}$ \\
HRT & $\approx 10.6 \mathrm{~h}$ \\
Flat-plate membrane & Sinap-25-PVDF $(0.34 \mathrm{~m} \times 0.47 \mathrm{~m} \times$ \\
& $0.07 \mathrm{~m})$, pore size $\leq 0.1 \mu \mathrm{m}$ \\
Module & 10 sheets $(\mathrm{m} 01-\mathrm{m} 10)$ \\
Flux & $20 \mathrm{~L} /\left(\mathrm{m}^{2} \cdot \mathrm{h}\right)$ \\
Aeration intensity & Membrane tank: $5.4 \mathrm{Nm}^{3} / \mathrm{h}$ \\
& $\left(\right.$ recommended by SINAP $\left.{ }^{\circledR}\right)$ \\
& Aeration tank: $1.30 \mathrm{Nm}^{3} / \mathrm{h}(\mathrm{DO} \geq 2 \mathrm{mg} / \mathrm{L})$ \\
Diffuser & Distance from tank bottom: $0.05 \mathrm{~m}$
\end{tabular}

HRT: hydraulic retention time; PVDF: polyvinylidene difluoride. 


\section{CFD modeling}

The commercial CFD code ANSYS Fluent ${ }^{\circledR}$ was used to simulate the 3D flow field. Before the hydrodynamic modeling, a 3D AEC-MBR was designed with the geometrical configuration described in Table 1, and the mesh was generated with a minimal element size of $2 \mathrm{~mm}$, as shown in Figure 1(b). According to Brannock's worst-case scenario comparison, the positive buoyancy forces from rising bubbles was much greater than the negative buoyancy forces from settling sludge (Brannock et al. 20IOa, b), so the three phases in MBR were simplified, only including liquid and gas phases in the CFD model. To describe the multiphase flow, the volume-of-fluid (VOF) twofluid model was adopted as coarse bubble aeration was supplied to the membrane tank. The VOF model was applied to immiscible fluids with particles larger than the grid size (Ndinisa et al. 2005; Ratkovich et al. 2009; Buetehorn et al. 20I). The continuous phase was the water/sludge mixture and the dispersed phase was air. The physical properties of the gas phase (i.e. density and viscosity) were set as air and those of the liquid phase were set as water. The standard $k-\varepsilon$ model was used for modeling the turbulence. For solver schemes, PISO was used for pressure-velocity coupling. PRESTO!, First Order Upwind, and Geo-Reconstruct were selected for pressure, momentum, and volume fraction, respectively; in addition, the First Order Upwind was used for turbulent dissipation rate discretization. The air diffuser through which the gas enters the column was treated as the surface with inlet flow rate of air equivalent to superficial gas velocity. Due to the unsteady behavior of the slug flow (different bubble size, shape and coalescence), a volume fraction of gas was defined to initialize the bubbles at the inlet boundary. The top wall of the column (the tank surface) was specified as a pressure outlet boundary condition. Considering the permeate flux $\left(10-20 \mathrm{~L} /\left(\mathrm{m}^{2} \cdot \mathrm{h}\right), 2.7-5.6 \times 10^{-6} \mathrm{~m} / \mathrm{s}\right)$ was much less than CFV $(>0.1 \mathrm{~m} / \mathrm{s})$, the boundary condition of the membrane surface was set as that of the tank walls, which were impermeable, stationary, free slip for air and no slip for water (Ndinisa et al. 2006; Yang et al. 2012). The time steps for simulations were $0.005 \mathrm{~s}$. Residuals that were used for convergence of mass, momentum, $k$ and $\varepsilon$ were default $\left(1 \times 10^{-3}\right)$. The simulation continued until the solutions converged.

\section{RESULTS AND DISCUSSION}

\section{Effect of $h_{m}$ on membrane fouling control}

The height of the gas-liquid mixing zone $\left(h_{m}\right)$ was the distance from the diffuser to the membrane module bottom
(Figure 1(a)). The effects of $h_{m}$ on velocity distribution at the membrane surfaces were studied. At a fixed top depth A $(300 \mathrm{~mm})$, five cases were simulated with the ratio $h_{m} / B$ set at 0.20, 0.32, 0.46, 0.55 and 0.60, respectively (Figure 1, $\mathrm{B}$, total static depth). In this study, CFV was used as the evaluation parameter for membrane fouling, as much research has proven that low $\mathrm{CFV}$ led to more serious membrane fouling (Chang et al. 2002; Choi et al. 2005).

Figure 2(a) shows the average CFV at 10 membrane surfaces. It can be found that the CFV between membrane sheets showed obvious non-uniformity that was higher at the central sheets and much lower at the side ones at $h_{m} /$ $B$ of 0.32 or less, which implied that the gas-liquid was not mixed fully in the short $h_{m}$. When $h_{m} / B$ increased to 0.55-0.6, almost all the membrane sheets were covered by a more uniform CFV, which was beneficial to generate uniform shear force at the membrane surface to control membrane fouling. The CFV distribution change can also be seen clearly in Figure 2(b), showing that higher $h_{m} / B$ led to more uniform CFV distribution. From Figure 2(a), it is noteworthy that CFV was lower for membranes 6-10 compared to membranes $1-5$ when $h_{m} / B$ was 0.32 and 0.20 , but for $h_{m} / B$ at 0.46 and 0.55 the phenomenon was opposite. It might be explained by the mixture rising direction shifting along with the increasing rising velocity. With the functioning of the baffle, the lower velocity mixture had to climb over the baffle and tended to shift toward channels close to the baffle; when the velocity increased enough to lift the free surface of the membrane tank, the mixture would flow from the membrane tank to the aeration tank along the free surface, then the back flow would happen from the aeration tank to the membrane tank along the baffle, which may result in the main stream in the membrane tank shifting toward membrane channels away from the baffle (Figure 2(a)). As shown in Figure 2(b), another finding was that the non-uniform CFV not only existed among different membrane sheets, but it also occurred at every single membrane surface. In conclusion, non-uniformity of CFV was a common phenomenon in membrane modules, which was quite harmful for membrane fouling control.

We also found the non-uniformity of gas-liquid flow in channels between two membranes (Figure 3). The flow velocity was higher in the middle of the channel, while a boundary layer with much lower velocity existed near the membrane surface, which might be another important reason for severe membrane fouling and loss of effective filtration area.

Based on the above discussion, a summary can be drawn that non-uniformity of CFV was an essential phenomenon occurring in the flat-plate membrane modules. However, 
(a)

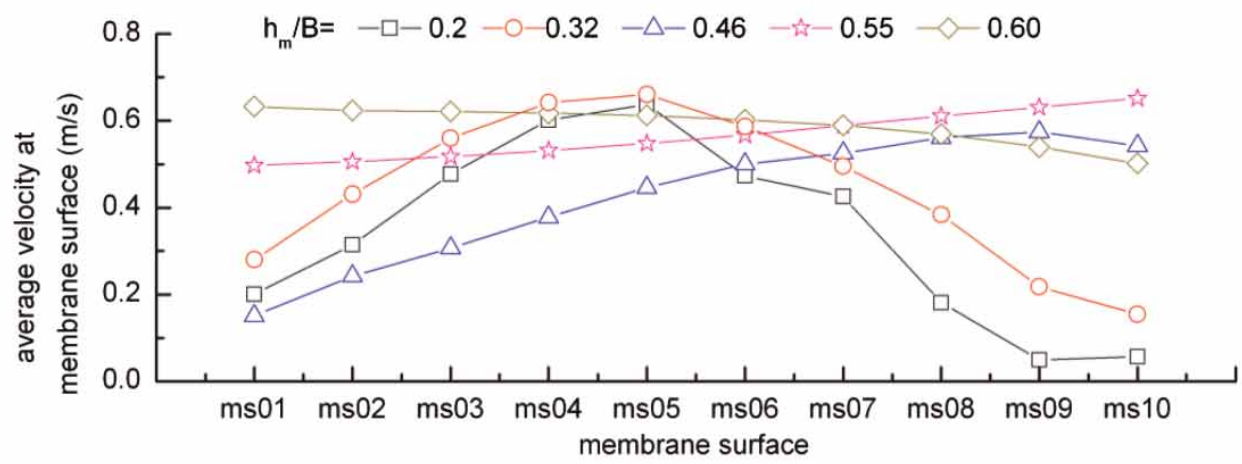

(b)

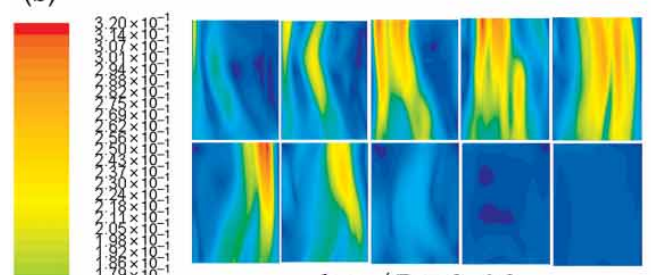

$\mathrm{hm} / \mathrm{B}=0.20$

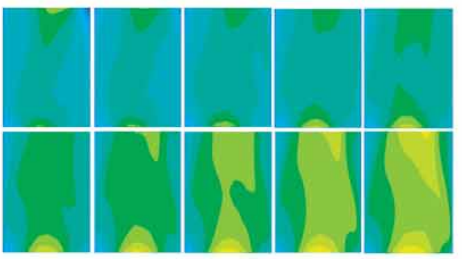

$\mathrm{hm} / \mathrm{B}=0.55$

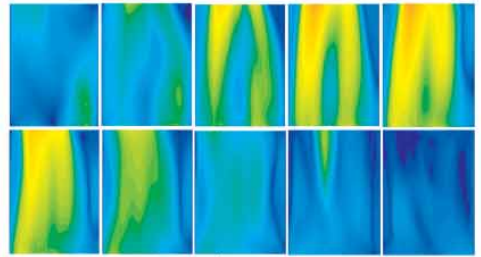

$\mathrm{hm} / \mathrm{B}=0.32$

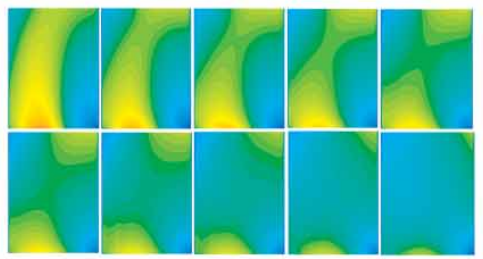

$\mathrm{hm} / \mathrm{B}=0.60$

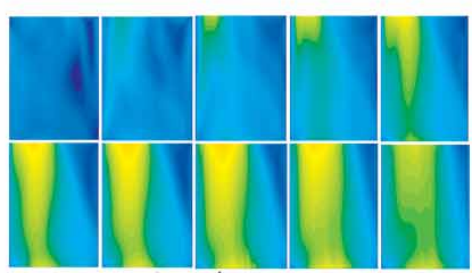

$\mathrm{hm} / \mathrm{B}=0.46$

Figure 2 | Distribution of velocity at membrane surfaces: (a) velocity curve, (b) velocity contour (for each set of 10 velocity contours, top row corresponds to membranes m01 to m05 and bottom row corresponds to membranes m06 to m10, left to right).

this problem could be solved by increasing the $h_{m}$ to an optimum range with the dimensionless parameter $h_{m} / B \geq 0.55$.

\section{Role of $\mathrm{H}$ circulation pipe}

Although HCPs have been used in AEC-MBRs, whether they were indispensable or not was unknown. In this study, two HCPs were installed in the modeled AEC-MBR (Figure 1), and the hydrodynamics with and without HCPs was simulated and analyzed. Figure 4 shows the velocity contour and path-line of the MBR system with and without HCPs. Although an obvious circulation velocity can be seen in Figure 4(a) (right), the circulation was ineffective without HCP, because the path-line in Figure 4(b) (right) shows that the circulation occurred mostly between the membrane tank and the top of the aeration tank. According to simulation results, the effective circulation rate between the two tanks without HCP was only 5.6\%, while it could reach $29 \%$ when the system was coupled with HCPs. In conclusion, the HCPs were necessary components and played an important role for circulation between the membrane tank and the aeration tank in AEC-MBR.

The effect of HCPs with different diameters on circulation is also discussed in this study. The diameter (d) and number of HCPs were set as $25 \mathrm{~mm} \times 2,32 \mathrm{~mm} \times 2,40 \mathrm{~mm} \times 2,50 \mathrm{~mm} \times$ 2, $65 \mathrm{~mm} \times 2,65 \mathrm{~mm} \times 3$, and $65 \mathrm{~mm} \times 4$, respectively. Then the ratio of $D / L$ was $11.1,14.2,17.8,22.2,28.9,43.3$ and $57.8 \%(D$, the sum diameter of HCPs, $D=2 \times d, 3 \times d$ or $4 \times$ $d ; L$, the baffle width). Figure 5 (left) shows the relationship between the flow rate of $\mathrm{HCP}$ and $D / L$. It can be found that the dependency of flow rate on HCP diameter had two regions, an increasing region and a plateau region. At the beginning, the increase of the diameter of HCPs led to a fast increase of the circulation flow rate. When $D / L$ was increased up to $50 \%$, the circulation rate was not overly sensitive to continually increasing diameter; it approached the maximum circulation rate of AEC-MBR under certain aeration intensity.

In application, larger HCPs can enhance the circulation between the membrane tank and the aeration tank, but on the other hand a larger space of the membrane tank is 

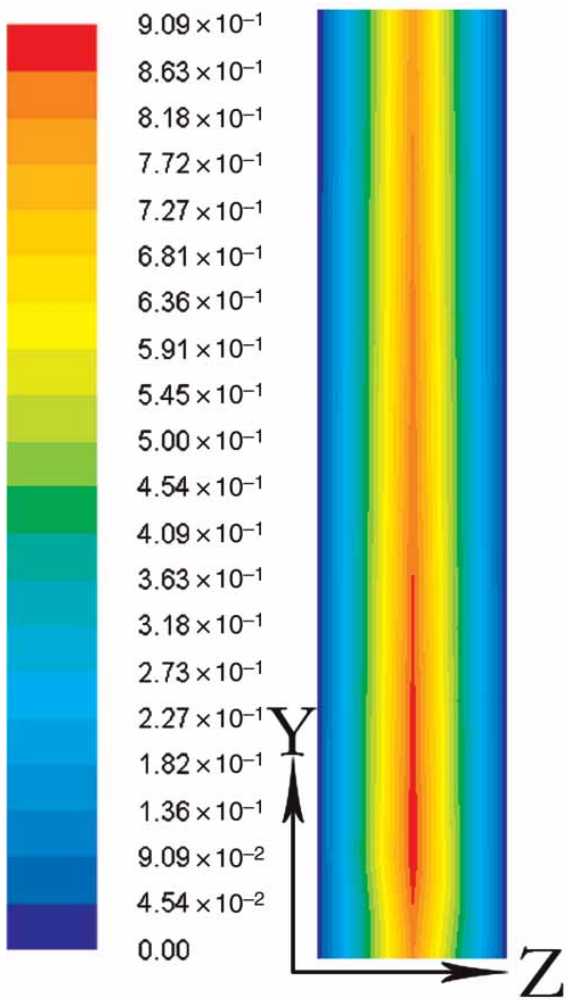

Figure 3 | The velocity contour between membrane sheets m05 and m06. needed to accommodate the membrane modules and the larger HCPs, which will not only increase the capital cost but also limit the circulation efficiency, as the compact membrane tank could improve the circulation of the MBR based on the team's research results. So, it is necessary to optimize the diameter of HCPs. Figure $5(b)$ shows the change of average flow velocity in $\mathrm{HCP}$ along with $D / L$. It can be noted that the average flow velocity reached a maximum when $D / L \approx 22.2 \%$, and on this $D / L$ ratio the optimized diameter of HCPs can be determined in the designing of the AEC-MBR.

\section{Validation}

In order to validate rationality of the model, two calibrations were carried out.

(1) The membrane tank alone was simulated first. A membrane tank was manufactured and operated, and the velocity in it was measured by a SonTek acoustic velocimeter (Flow Tracker). Along the center $\mathrm{X}$-axis five sampling points were located at the same water depth above the module, each point measured four times. According to the results shown in Figure 6(a), the (a)

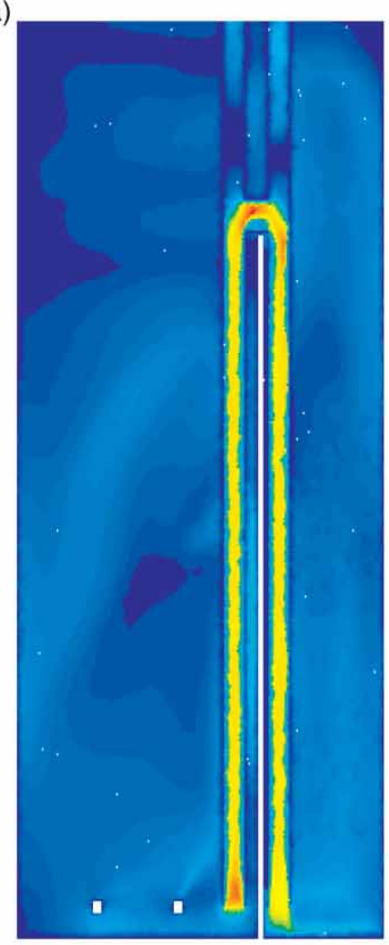

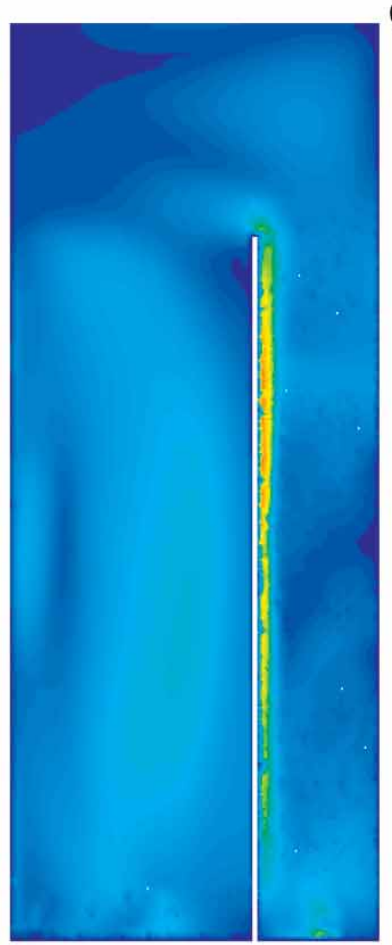

(b)
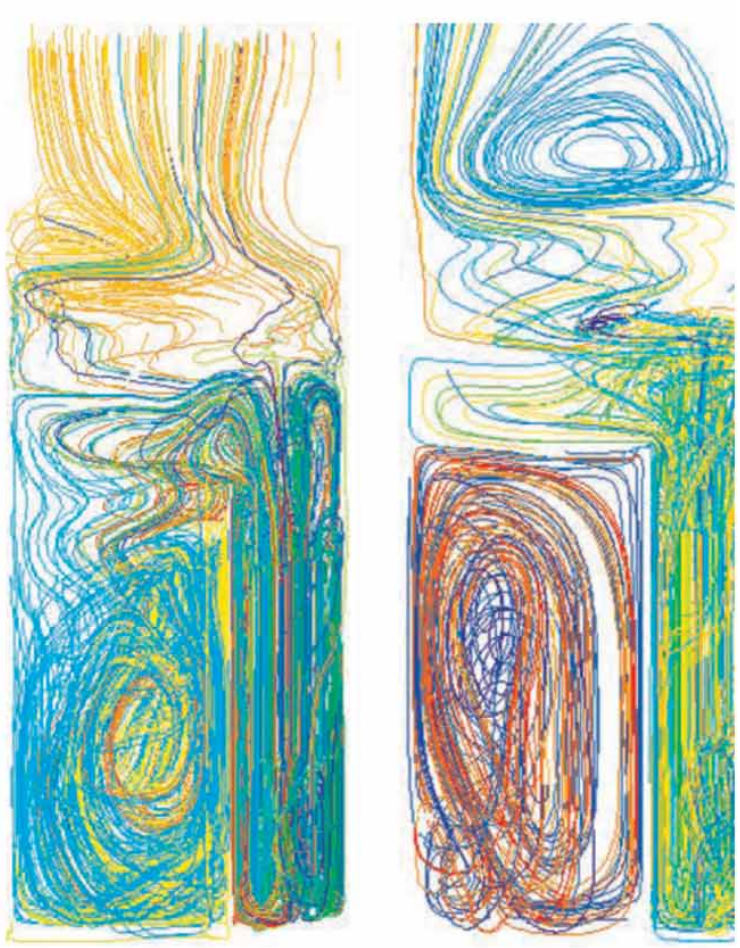

Figure 4 | Function of HCP in AEC-MBR. (a) Velocity contour at cross-section of HCP. (b) Path-line at middle cross-section (left: with HCPS, right: without HCPS). 
(a)

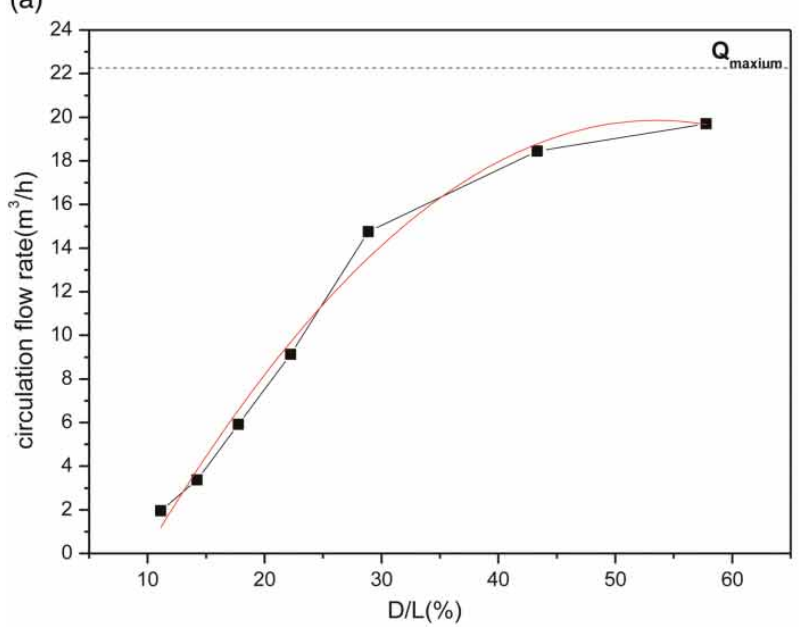

(b)

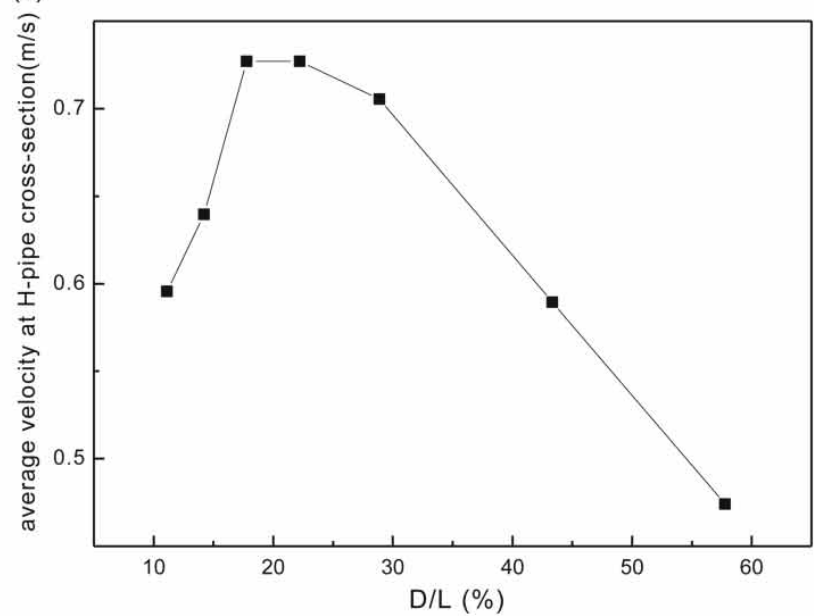

Figure 5 | (a) Variation of flow rate with D/L of HCP. (b) Average flow velocity at HCP cross-section with different D/L of HCP.

computation agreed with the experimental results with a maximum error of $29.6 \%$, which is considered to be acceptable. The discrepancy between the measured and predicted velocity was attributed to the fact that the velocimeter was handheld and its probe was relatively large compared to the tank size, and the actual low velocity might also be affected by instrumental sensitivity. From Figure 6(a), another similar trend can be found in that the experimental and CFD data showed the same bimodal distribution, which was caused by two higher flow velocity zones right above two aerators installed at certain intervals in the membrane tank.

(2) Under the same aeration intensity, the simulated velocity had the same range as that from measurements. In the experiment, the up-flow velocities of the mixture were measured under different aeration intensities in an experimental AEC-MBR. When aeration intensity changed from 1 to $23 \mathrm{~m}^{3} /\left(\mathrm{m}^{3} \cdot \mathrm{h}\right)$, the measured up-flow velocity ranged from 0.2 to $0.5 \mathrm{~m} / \mathrm{s}$ (Figure 6(b)) (Gang 2006). For simulations with the same aeration intensity range, the computed velocities presented from 0.2 to $0.6 \mathrm{~m} / \mathrm{s}$, which also suggested a good agreement with the experimental data.

From comparisons between simulation and experiment, it is believed that the model applied in this paper had the capability to provide reasonably accurate simulation results. We realize the limitations of our current approach in model validation; however, more in-depth measurements were not available in the present experimental set-up, and a detailed

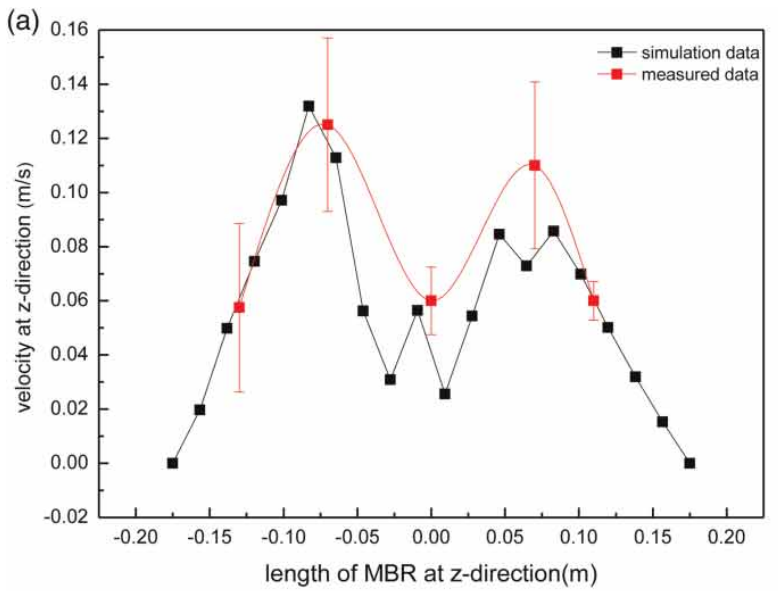

(b)

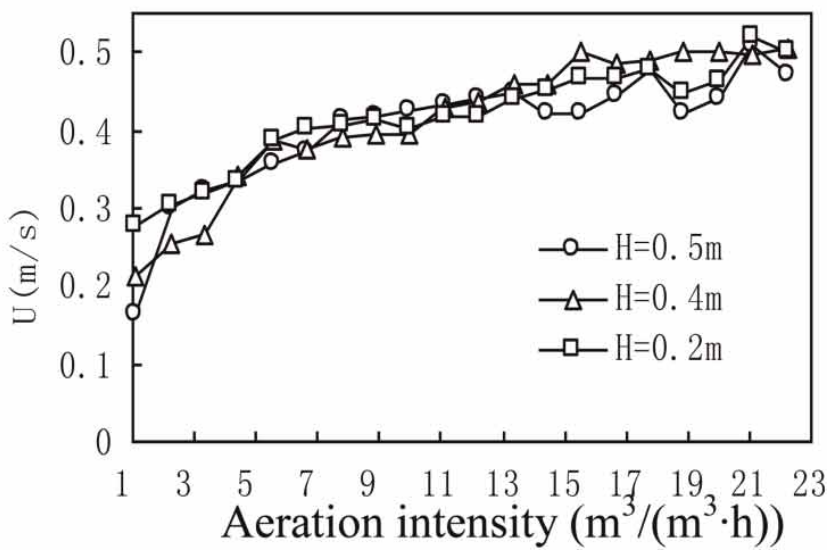

Figure 6 | (a) Comparison between modeling velocity and measured velocity of an immersed MBR. (b) Up-flow velocities of mixture under different aeration intensities in an experimental $\operatorname{AEC}-\mathrm{MBR}(\mathrm{H}$, the height of the velocimeter located in the membrane tank). 
particle-image velocimetry flow experiment and model verification will be conducted in the near future.

\section{CONCLUSION}

This paper studied the hydrodynamics in AEC-MBR by CFD and the findings can be concluded as follows. (1) Nonuniformity of CFV was an essential phenomenon occurring in the flat-plate membrane modules, which may be an important reason for membrane fouling in MBR application. However, this problem could be alleviated by increasing the height of the gas-liquid mixing zone $\left(h_{m}\right)$ to an optimum range. (2) The HCP played an important role in making circulation effective in the AEC-MBR. When HCP is designed with $D / L \approx 22.2 \%$, a most efficient circulation would be available. In this study, the CFD modeling results were successfully validated against experimental results. The results would provide technical support for design of MBRs, and the research method provided by this paper could be a reference for further hydraulic study on MBRs.

\section{ACKNOWLEDGEMENT}

This work was funded by the National Natural Science Foundation of China-Research on the Relationship between Flow Field, Mass Transfer and Energy Consumption in MBR (No. 51278483).

\section{REFERENCES}

Brannock, M. W. D., De Wever, H., Wang, Y. \& Leslie, G. 2009 Computational fluid dynamics simulations of MBRs: Inside submerged versus outside submerged membranes. Desalination 236 (1-3), 244-251.

Brannock, M., Leslie, G., Wang, Y. \& Buetehorn, S. 2oroa Optimising mixing and nutrient removal in membrane bioreactors: CFD modelling and experimental validation. Desalination 250 (2), 815-818.

Brannock, M., Wang, Y. \& Leslie, G. 20Iob Mixing characterisation of full-scale membrane bioreactors: CFD modelling with experimental validation. Water Res. 44 (10), 3181-3191.

Buetehorn, S., Volmering, D., Vossenkaul, K., Wintgens, K., Wessling, M. \& Melin, T. 2OI CFD simulation of singleand multi-phase flows through submerged membrane units with irregular fiber arrangement. J. Membr. Sci. 384 (1-2), 184-197.
Chang, I.-S., Le Clech, P., Jefferson, B. \& Judd, S. 2002 Membrane fouling in membrane bioreactors for wastewater treatment. J. Environ. Eng. 128 (11), 1018-1029.

Choi, H., Zhang, K., Dionysiou, D. D., Oerther, D. B. \& Sorial, G. A. 2005 Influence of cross-flow velocity on membrane performance during filtration of biological suspension. J. Membr. Sci. 248 (2005), 189-199.

Fan, Y. B., Li, G., Wu, L. L., Yang, W. B., Dong, C. S., Xu, H. F. \& Fan, W. 2006 Treatment and reuse of toilet wastewater by an airlift external circulation membrane bioreactor. Proc. Biochem. 41 (6), 1364-1370.

Gang, L. 2006 Theoretical Study and Optimization of the Airlift External Circulation Membrane Bioreactor. PhD thesis, Research Center for Eco-Environmental Sciences, Chinese Academy of Science, Beijing, China.

Judd, S. \& Judd, C. $20 I I$ The MBR Book - Principles and Applications of Membrane Bioreactors for Water and Wastewater Treatment. Elsevier, Oxford, UK.

Kang, C. W., Hua, J. S., Lou, J., Liu, W. J. \& Jordan, E. 2008 Bridging the gap between membrane bio-reactor (MBR) pilot and plant studies. J. Membr. Sci. 325 (2), 861-871.

Khalili-Garakani, A., Mehrnia, M. R., Mostoufi, N. \& Sarrafzadeh, M. H. 20II Analyze and control fouling in an airlift membrane bioreactor: CFD simulation and experimental studies. Proc. Biochem. 46 (5), 1138-1145.

Ndinisa, N. V., Wiley, D. E. \& Fletcher, D. F. 2005 Computational fluid dynamics simulations of Taylor bubbles in tubular membranes - model validation and application to laminar flow systems. Chem. Eng. Res. Des. 83 (A1), 40-49.

Ndinisa, N. V., Fane, A. G., Wiley, D. E. \& Fletcher, D. F. 2006 Fouling control in a submerged flat sheet membrane system: Part II - Two-phase flow characterization and CFD simulations. Separ. Sci. Technol. 41 (7), 1411-1445.

Nguyen Cong Duc, E. C. L. 2007 CFD applied on MBR system. First Conference on CFD Modeling for MBR Applications: From the Fibre to the Plant, Berlin, Germany.

Nguyen Cong Duc, E. C. L., Lesjean, B., Essemiani, K. \& Hohman, B. 2008 CFD applied to membrane bioreactor upstream R\&D industrial application. Second Conference on CFD Modeling for MBR Applications: From the Fibre to the Plant, Ghent, Belgium.

Prieske, H., Drews, A. \& Kraume, M. 2008 Prediction of the circulation velocity in a membrane bioreactor. Desalination 231 (1-3), 219-226.

Ratkovich, N., Chan, C. C. V., Berube, P. R. \& Nopens, I. 2009 Experimental study and CFD modelling of a two-phase slug flow for an airlift tubular membrane. Chem. Eng. Sci. 64 (16), 3576-3584.

Saalbach, J. \& Hunze, M. 2008 Flow structures in MBR-tanks. Water Sci. Technol. 57 (5), 699-705.

Yang, J., Vedantam, S., Spanjers, H., Nopens, I. \& Jules, B. 2012 Analysis of mass transfer characteristics in a tubular membrane using CFD modeling. Water Res. 46 (15), 4705-4712. 